\title{
What is appropriate and relevant assistance after a disaster? Accounting for culture(s) in the response to Typhoon Haiyan/Yolanda.
}

\author{
Jessica Field
}

(Published in the International Journal of Disaster Risk Reduction, Vol. 22, June 2017)

\begin{abstract}
Typhoon Haiyan, known locally as Yolanda, was one of the strongest typhoons to hit the Philippines in recent history, killing over 6000 people when it made landfall in November 2013. The international humanitarian response was fast and expansive, with post-response evaluations noting it as largely successful. This study, however, reveals a disconnect between international humanitarian and affected-community understandings of effectiveness, and roots the division in an under-acknowledged difference of cultures between the international humanitarian system and the people receiving assistance. Challenging official humanitarian framings of appropriateness and relevance, this study posits the need for a more localised, contextualised and culturally-sensitive approach to understanding post-disaster needs and vulnerabilities.
\end{abstract}

Keywords: Disasters, Humanitarian, the Philippines, Typhoon Haiyan, Vulnerability, Culture.

\section{Introduction}

On 8 November 2013 the Philippines experienced one of the strongest typhoons to make landfall on record. Known locally as Yolanda and internationally as Haiyan, the typhoon ravaged a substantial part of the Visayas region, killing over 6,000 people, displacing 4.1 million and affecting a total of 14.1 million (OCHA 2013). The Government of the Philippines (GoP) called for international assistance, the United Nations cluster system was activated, ${ }^{1}$ and organisations from across the world offered aid and support, working together with national and local counterparts. Subsequent evaluations have noted the response broadly as 'timely and relevant' (IASC 2014) with the efficient deployment of pre-positioned relief goods such as food and shelter kits down the supply chain, and their clearance at sites in-country (ACF 2013). It was also described as 'effective ... with various opportunities for learning at the global level' (Oxfam 2016). Several aid workers noted that they 'were struck by the frequent

\footnotetext{
${ }^{1}$ The UN cluster system is a coordinating apparatus for humanitarian organisations - UN and non-UN - designed to more effectively manage 'the main sectors' of humanitarian health, e.g. shelter, health, livelihoods and logistics (UNOCHA 2016). This system coordinated the thrust of the international response to the typhoon.
} 
expressions of gratitude they encountered' from affected communities over the course of their time in the Philippines (ALNAP 2015). However, despite praise for the timeliness and scale of support, and criticisms for some of the technical and coordination difficulties, there was an aspect of assistance appraisal that did not receive so much attention: namely, the appropriateness and relevance of the aid in relation to individual and community nonsubsistence needs and priorities. More specifically, interviews undertaken as part of field research for this study revealed a disconnect between international humanitarian understandings of what would be the most appropriate (and therefore the primary) support to aid recovery, and affected-Filipino understandings of effectiveness. Interrogation of this disconnect will form the substance of this article, but first let me begin with an illustrative story.

Just one month after Yolanda hit, the GoP's Department of Social Welfare and Development (DWSD) and the Department of Education (DepEd) gathered local teachers, volunteers and government workers together for a day of pampering in the province of Leyte. These groups of people - simultaneously victims and humanitarian responders - were treated to free haircuts, given free cosmetics, and entertained by famous Filipino artists, including Aiza Seguerra. According to Government officials, this was inspired by DepEd Secretary, Brother Armin Luistro's encounter with a teacher from Tacloban whom he met just a few days after the typhoon made landfall (Interview, 2016). Luistro observed that she was wearing lipstick and, taken by surprise, asked her why. Her response, he recalled, was 'Gusto ko Brother, kapag nakita ako ng mga students ko sa pagsimula ng klase, maayos ang itsura ko. Gusto kong isipin nila na nakabangon na ako para sila rin, ma-inspire na bumangon (Brother, I want to look good when my students will see me. I want them to think that I have recovered so that they will be inspired to also move on)' (Department of Social Welfare and Development, Philippines 2013). Local DepEd staff interviewed as part of this research and also treated to the experience recalled that 'it was very effective; it was a month after Yolanda, people didn't have these things'; and a local NGO worker later explained to me that its importance in boosting a community sense of recovery was in the sense of dignity that wearing cosmetics brought, particularly for teachers, as lipstick is strongly associated with female teachers in the Philippines, almost as a part of the uniform.

That the teaching professionals recalled their pampering session as 'effective' humanitarian assistance in the aftermath of the typhoon suggests an experience of needs, vulnerability and recovery among these women that is worth examining. It hints at an understanding that links post-disaster recovery experience not only to a sense of dignity in 
terms of appearance and 'feeling human' again, but also to a status-identity connected to social and community structures (i.e. a status and identity as teachers that can inspire students by presenting some return to normalcy).

The definitional debates around the term 'dignity' are beyond the remit of this paper. Suffice to say that it is generally - and not unproblematically - understood as universal, a right of humankind (United Nations 1948), and an important attribute of 'political life' that separates it from 'bare', or simply biological human existence (Fiori et al 2013). The concept should be understood in multiple ways relating to the values and histories of particular societies. In other words, dignity is a culturally embedded value and idea. Thus, as anecdotes and appraisals of humanitarian aid invoking dignity and community status came to the fore of this and other interviews, the 'cultural' aspects of the experience of Filipinos affected by this typhoon - both aid workers and citizens - took precedence. Questions arose over the extent to which different cultural values and norms were accounted for in the response to the typhoon, and whether that recognition informed programming. Where there was a clash in understandings of what humanitarian objectives should have been - due to differing values and perspectives between some international humanitarian organisations and parts of Filipino society - why did certain understandings of effectiveness 'win out' over others? Local needs and priorities are certainly prominent in development and assistance frameworks, particularly in the 'appropriateness' and 'relevance' criteria for evaluations (Beck 2006). Nevertheless, a central focus of the field research, and therefore the subject of this paper, has been to explore whether there is a disconnect in local and international understandings of these concepts as they determine action - such as assessing need and measuring vulnerability - and what the implications of that disconnect are.

Importantly, the aim of this paper is not to romanticise 'the local' and 'the international', nor is it to reduce and essentialise humanitarian responses to local=Filipino, international=foreign. Actors and movements recognised as local or international in a particular disaster response context - whether that be, for example, a town council, a national branch of an international aid agency, or the United Nations - are heterogeneous networks intertwined with other local and international actors and movements of varying scales (Lewis and Mosse 2006; Benadusi et al 2011: Part Two). Rather, the aim of this paper in using the broad descriptors of 'local' and 'international' is, firstly, as an analytical tool. In using those terms, it seeks to partly disentangle the key elements of the response so as to provide a frame for teasing out and analysing differing understandings of effectiveness held by grass-roots aid actors embedded in the disaster context, the typhoon-affected population, and external aid 
actors of the dominant international humanitarian system. The second aim is to analyse why there is a disconnect in those understandings. Thus, such a broad framing affords the opportunity to challenge the apparent universalism of dominant understandings of humanitarian need and vulnerability, and it highlights the necessity of reassessing ideas of what constitutes effective and relevant aid, and for whom.

The paper will begin with a note on the methodology of the study and an explanation of the key concepts and ideas. It will move on to contextualise disaster experiences and responses in the Philippines and will place the international response to Typhoon Yolanda within that context. This will be followed by a critique of dominant humanitarian aid targeting practices and the entrenched technocratic view of vulnerability as a determinant of that targeting. Finally, the article will end with some thoughts on re-approaching 'appropriateness' and 'relevance' with a more nuanced consideration of the various cultures of humanitarianism at play in a given disaster.

\section{Research Methodology and Concepts.}

\subsection{Research Methodology}

Field research for this study was undertaken in the Philippines between late January and late February 2015, in Manila (the capital city and location of many humanitarian organisations' headquarters), Tacloban (in the Eastern Visayas region, one of the worst affected areas) and Ormoc (a city also in the Eastern Visayas and badly hit by the typhoon). Interviews included four village community group discussions as well as two focus-group discussions with INGO aid workers in-country, and forty-five individual/small group interviews with foreign aid workers based in London, foreign aid workers based in the Philippines, national and local Filipino aid workers, local and national officials, academics based at the University of the Philippines, and a range of individuals affected by the typhoon.

\subsection{A Note on Concepts}

\subsubsection{Culture: A frame}

'Culture' is a particularly contested term as there is no single, universally accepted definition, and the analysis of culture, to quote Geertz (1973: 5), is an interpretive science 'in search of meaning' (Geertz 1973; 2000; Giddens 2009). Kreuter et al (2002:133) provide a useful framing of the concept for this paper, though it is by no means absolute:

[C]ulture is learned, shared, and transmitted from one generation to the next, and it can be seen in a group's values, norms, practices, systems of meaning, ways of life, and other social regularities. Factors such as familial roles, communication patterns, beliefs 
relating to personal control, individualism, collectivism, and spirituality and other individual, behavioral and social characteristics are not inherently "cultural" but may help define a culture for a given group if they have a special meaning, value, identity or symbolism to the group's members.

This framing is useful as it identifies aspects of a group that may be analysed in 'search of meaning', as noted by Geertz. A similar identification of 'cultural' factors is deployed in this paper's analysis of different humanitarian responses to the typhoon in order to identify characteristics of different humanitarian meaning and value systems. Of course, it must be noted that codifying such individual, behavioural and social characteristics can risk essentialisation and presenting the cultures of different groups as static or opposing (such as in the local versus international dichotomy) - this paper seeks to avoid such oversimplifications. Nonetheless, challenging the universalism of dominant understandings of humanitarian effectiveness requires a closer look at how different groups frame effectiveness differently due to viewing disasters through their own particular systems of meaning.

\subsubsection{Culture in Humanitarian Context}

The concept of 'culture' is gaining increasing traction in humanitarian studies and action (Hoffman and Oliver-Smith 2002), as a crisis-affected group's norms, values and meaning systems are recognised as being 'a significant factor in creating higher levels of vulnerability' for some members of that group, while established power systems can unequally distribute risk (quote: IFRC 2014; Douglas and Wildavsky 1983; Benadusi 2014). Culture is also noted (in health research in particular) as having health, risk asnd resilience implications more widely, in that it can determine the acceptance and adoption of humanitarian messaging and programming by individuals and groups (Kreuter et al, 2002:134; Douglas and Wildavsky). This is not to say that the formula for improving the effectiveness of humanitarian action for crisisaffected people therefore lies wholly with adapted targeting or tailoring approaches through translating one 'cultural language' - for example, the best practice humanitarianism of international non-governmental organisations (INGOs) - into another - for instance that of everyday life in a Filipino village. Such a deterministic approach would suggest an opposition between indigenous and 'expert' forms of knowledge, when these are actually neither mutually exclusive, nor fixed.

Rather, the importance lies in recognising that there are multiple and interrelated cultures at play in such a situation - at the level of the family and community, at regional and national levels, in Filipino humanitarian responses, foreign humanitarian responses, and so on. Thus the 'effectiveness' of a response may be understood by one group in one moment, for 
instance, as attaining its objectives in terms of meeting physiological and material needs in the emergency phase. It may be understood by another group as prioritising a return to social normalcy through the receipt of non-life saving items - such as cosmetics for teachers. Vulnerability in the first instance is understood in subsistence and biological terms, in the latter it is understood along socio-cultural lines in status terms. 'Effectiveness' may even be understood by the same group in those two different ways in different moments after a disaster; they are not mutually exclusive opposites but form part of a complex set of broader humanitarian frames, which ultimately affect people's experiences of being vulnerable, their attitudes towards a response, and their longer-term recovery (Heijmans 2009:4).

The necessity of accounting for social and cultural complexity in humanitarian assistance is acknowledged in the OEDC-DAC [Organisation for Economic Co-operation and Development's Development Assistance Committee] criteria for evaluating humanitarian responses, under the terms 'relevance' and 'appropriateness': 'Relevance is concerned with assessing whether the project is in line with local needs and priorities, as well as donor policy. Appropriateness is the tailoring of humanitarian activities to local needs, increasing ownership, accountability and cost-effectiveness accordingly' (ALNAP and Channel Research, n.d.). Although these definitions do call for a focus on local concerns, and policy documents relevant to these definitions do note the importance of paying attention to culture (Beck 2006:23), the actual understandings of needs and priorities that underpin them are rooted in a particular - and distinct - culture themselves. This can make 'tailoring' difficult in practice, as what might be defined a need and priority for some, such as lipstick, may not be as important to others in the same timeframe (Heijmans 2009) - for example, UN agencies and INGOs, which largely understand needs in subsistence, capacity, and rights terms, for instance. This will be returned to in more detail below.

Why do such clashes of priorities occur, and what are the implications? Do 'appropriateness' and 'relevance' need revisiting in humanitarian programming to prioritise a consideration of non-subsistence and non-life-saving cultural values? The need for a lifesaving and subsistence focus in the acute emergency phase of a disaster such as Yolanda is certainly not in question; the author recognises that resource constraints have a large role to play in determining what is and is not possible. Nevertheless, these questions of different selfand community-conceptions of need and vulnerability contribute to a larger picture of contrasting understandings of 'effectiveness', particularly where meeting 'need' - however defined - is a key criteria for success.

\section{Contextualisation of Disasters in the Philippines.}




\subsection{Everyday Disasters}

Disasters such as earthquakes, typhoons, tropical storms, and volcanic eruptions are part of the fabric of everyday life in a country that famously sits on the Pacific 'Ring of Fire' (Bankoff 2003; Wisner et al 2004; van Voorst et al 2015). Typhoon Yolanda was not the only large-scale disaster to affect the Philippines in 2013. In the early months of that year, Filipinos were still recovering from Typhoon Bopha, which made landfall in December 2012. In August 2013, Central Luzon experienced tropical cyclone Utor - locally known as Labuyo - which, although it was given relatively little attention in the international media, resulted in the evacuation and destruction of the residences of many Filipinos. In October, just a month before Yolanda, the Central Visayas region experienced the Bohol earthquake, which affected more than 670,000 families (IFRC 2014). On average, six to nine typhoons make landfall every year in the Philippines (Wingard et al 2013). Thus, every day there are families throughout the country's 7,107 islands reconstructing and improving their lives following recent and long-past disasters, often simultaneously preparing for future ones.

This everyday nature of disaster experience certainly does not diminish its impact on the lives of Filipino citizens. Acknowledging its centrality involves a testament to the strength and resilience of communities that have continued to inhabit and survive, and in many cases thrive, in disaster-prone areas over the centuries; but it also involves recognition of the precarious situation of many who are trapped in chronic poverty; a social condition that is perpetuated by recurrent disaster and exacerbates the impact of future disasters.

That 'the natural' and 'the social' cannot be separated from one another in reflections on the human impact of disasters has been long discussed in the social sciences (Oliver-Smith and Hoffman 1999; Hoffman and Oliver-Smith 2002; Wisner et al 2003:5; Stromberg 2007:199-122), and is increasingly recognised by national governments and international humanitarian organisations (Sanderson et al 2002). In humanitarian discourse, this recognition has been reflected partly through a characterisation of disasters as being shaped by 'hazard', 'vulnerability' and 'capacity', and for the reduction of risk to involve changes in social circumstances and behaviours (UNISDR 2007; UNISDR n.d.; WCDR 2015). In 1978, the GoP enacted Presidential Decree No. 1566, which called for the strengthening of Filipino disaster control and capability, and 'emphasised self-reliance by encouraging self-help and mutual assistance' (Fernandes et al, 2012:2014). The government set up the National Disaster Coordinating Council that same year, which was renamed in 2010 as the National Disaster Risk Reduction Management Council, following the country's enactment of the internationally lauded Disaster Risk Reduction and Management Act (2010) (Gaillard et al 2014). Building 
upon this Act, government, international, national and local agencies have been able to undertake and mainstream longer-term disaster risk-reduction (DRR) activities in the Philippines that cross over with what might be more traditionally understood as development programming (Government of the Philippines 2010).

Disasters here in the Philippines are not seen as unexpected accidents, but as tied into pre-disaster community vulnerabilities and capacities (Heijmans 2009). What the GoP recognised with such measures is that development programmes and humanitarian activities should complement one another in tackling everyday dangers and stresses and in addressing the shocks of disasters, both before they occur and after they hit. The GoP has sought to mainstream resilience-building and DRR in development planning across every level of government, investing almost US\$800 million per year - no small sum for a middle income country, particularly in light of the international community's 'notoriously poor support' for DRR mechanisms (Peters and Budimir 2015:5).

Such resilience-building and risk-reduction approaches to tackling the impacts of disasters reflect the global shift away from understanding them as 'unusual occurrences' that required rescue- and protection-orientated responses - termed the modernist approach of pre-1970s humanitarianism - towards post-modern approaches that recognise the interaction between disasters and individual and family positions of socio-economic disadvantage (Duffield 2013:5). In terms of disaster management, this shift has resulted in tacit recognition that what renders a community vulnerable to disaster is its relative position of disadvantage within a society; and this has subsequently led to a focus on social adaption and self-entrepreneurialism in preparedness, resilience-building and risk-reduction (Duffield 2013:5). In terms of disaster response, it has resulted in vulnerability- and needs-assessments post-disaster, and the distribution of emergency aid based on targeting and prioritising the most socioeconomically disadvantaged and marginalised in an affected community. As such, the priorities of both post-modern disaster management and disaster response are the same. When asked what an effective humanitarian response entails, various international and national NGO workers based in the Philippines, who had worked in the response to Yolanda, explained that it involved 'ongoing assessments to keep on top of arising needs', 'targeting particularly vulnerable populations', 'capacity building' and 'improving resilience'. The vocabulary here reveals a relationship between resilience-building approaches of disaster management and targeting priorities during a disaster response.

Nevertheless, while this shift of focus from reactive protection to an emphasis on preand post-disaster socio-economic vulnerabilities and capacities might be a step in the right 
direction (Bankoff 2004:25), disaster management and response discourses still largely continue to approach these aspects of disasters in ways that are systematic, activity-oriented, time-bound, measurable, and implicitly focused on socioeconomic productivity. In other words, largely distinct from everyday local politics, values and meaning systems. In line with the evolving development discourse of the 1980s, disaster management developed a neoliberal hue, emphasising the importance of choices made by the poor in shaping their own outcomes; activities were increasingly designed around notions of social capital and the way in which the poor manage human and natural resources (Nakagawa and Shaw 2004:7).

\subsection{Social Capital and Disaster Recovery.}

The idea was - indeed, still is - that high levels of trust, social norms and networks, key tenets of social capital, 'can be measured and a high accumulation of such capital contributes significantly to social, political and even economic performance' (Nakagawa and Shaw 2004:7). In this approach, the motives of the social are reduced to economic terms, which has impacted understandings of disaster resilience and recovery. For instance, under the definition of disasters given by the United Nations International Strategy for Disaster Reduction (UNISDR) and used by the GoP to inform official disaster management policies (GoP 2010), the severity of impact on a given community is exacerbated in part by 'insufficient capacity or measures' with which to cope or reduce risks associated with disasters. Here capacity refers to 'physical, institutional, social or economic means [to reduce the levels of risk or effects of a disaster] as well as skilled personal or collective attributes such as leadership and management' (OECD-DAC 2006). As such, 'capacity' is about individual and social-network adaptability - an adaptability that is determined by entrepreneurial economic development, physical structures, human capital and governance (Manyena 2014:2). The word 'insufficient' in this definition of disasters suggests that, where negative impacts have occurred, there was just not enough capacity - i.e. social capital - in quantity and/or quality and that communities would have been able to cope afterwards or reduce risks beforehand had there simply been more.

In disaster response terms, because an affected community is viewed as already vulnerable, with its existing capacity proven 'insufficient' by the facts of both the negative effects of a disaster and the subsequent call for assistance, 'sufficient capacity and capability' therefore become implicit determinants of the response hierarchy, i.e. the organisation of authority in leading the disaster response and activity management. The countries that 'have' capacity assist those that 'do not' and, crucially, these actors assist according to their own 
understandings of recovery. While this makes sense in some ways - as disaster responses are certainly costly, and the affected community, after all, has been overwhelmed enough to call for assistance - the entrepreneurial adaptability imperative of post-modern disaster management and response discourses can result in an inadvertent dismissal of the role of non-economic local politics, values and meaning systems in boosting community resilience and coping, post-disaster. Such a consequence is further exacerbated by asymmetry in the humanitarian funding system, which often requires smaller, community-based NGOs to adhere to the economic and technocratic frames of the dominant disaster management discourse in order to secure funding by international donors. Heijmans (2009:14) offers a relevant example from her experience in the Philippines' community-based disaster risk management (CBDRM) circuit:

When writing proposals, we used language from disaster management literature and science. which resonates with CDRC's [Citizens Disaster Response Centre] political view on 'disaster' and 'vulnerability' and which provides CDRC with a distinctive identity and mandate to the network, and a framework to communicate with donors. Humanitarian language is used tactically vis-à-vis government forces and the military to create access to disaster and conflict affected communities, The [sic] pulling and hauling between these multiple realities - common in all organizations - often results in discomfort, and in contradictions between people's ideological beliefs and their day-to-day practices.

Such an application of dominant disaster management language and values in proposals and programming can result in a disaster response that may be appropriate and relevant in meeting immediate physical and material needs as determined through assessments and targeting activities - in OECD-DAC terms - but that potentially overlooks more locally-based and context-orientated elements of community cohesion and disasterrelated activities.

\subsection{The Politics of Resource Distribution}

In the response to Typhoon Yolanda there was an apparent disconnect between the disaster priorities of many affected Filipinos and the programming of an externally driven response applying the dominant disaster management formula. In the first instance, certain aspects of everyday politics were overlooked in the delivery of emergency aid and the subsequent initiation of recovery programmes. By reacting to the disaster as a large singular event and targeting individuals based on 'best-practice' definitions of need and vulnerability, the assistance given to communities following Yolanda was not tailored to alternative cultural 
understandings of recovery as informed by Filipino experiences of the disaster as a momentous but 'every day' event.

This was evident in the distribution of non-food items during the emergency phase and the livelihood assistance given during recovery. Affected communities interviewed as part of this research frequently expressed the wish that the emergency distributions following Yolanda had been uniform and equal across the community. 'We were happy to get less individually', reflected one woman from a Leyte barangay, 'as long as everyone in the community got the same'. Different items and levels of support were given to different community members according to the humanitarian practice of 'targeting', whereby distribution is determined - in theory at least - using a needs-based framework aimed at reaching the most vulnerable in a community. 'Beneficiaries' and those that didn't receive goods alike found the practice socially divisive due to its distortion of status in a given community. All four of the communities interviewed in Tacloban and Ormoc expressed discontent at the targeting processes, stating that they disagreed or were unhappy with INGO differentiation between the poorest of the poor, the poor and those who were not in such dire need, as this targeting did not always accord with community definitions of 'poor' and 'in need', nor with self-association with those terms. In one Tacloban community a councilor recalled frustration that his family had received nothing due to the fact that he had volunteered to assist INGOs with distributions, thereby excluding himself as a recipient under the apparent distribution policies of those INGOs. As a councilor with care-of-community responsibilities, he had naturally offered to help, but exclusion from distribution resulted in a sense of marginalisation and separation from the community's recipients.

A recent research project looking at accountability to affected populations after the typhoon, the Pamati Kita project, has found similar experiences among affected community members (Jacobs 2015). Pamati Kita researcher Jonathan Corpus Ong recently noted that 'differentiated humanitarian relief within small communities sparks status anxiety. Intensified by traditional Filipino village relations where neighbours are regarded as extended family and people's sense of dignity (pagkatao, in Tagalog) is defined by their status in the community, status differences marked by small luxuries hit hard on the have-nots. Those excluded from livelihood-project income borrow money from relatives and incur debt in efforts to keep up with neighbours' vegetable gardens and Christmas lanterns' (Corpus Ong 2015; see also Gamburd 2014 [Chapter 7] for an analysis of the status anxiety of 'the aid gift' in Sri Lanka post-2004 Tsunami). 


\subsection{Kinship}

This issue of status anxiety must be placed in the context of wider Filipino culture and history in order to be appreciated in a disaster context (Lim 2008). As noted by Corpus Ong et al (2015), neighbours are regarded as extended family in Filipino society. Children continue to be a part of their natal family even after marriage, and 'people who are not biologically related can make new claims on each other through fictive kinship, which creates ritual brothers, godmothers, and godfathers' (Abilnales and Amoroso 2005:48). This sense of family spans both the private and public realms, as contemporary indigenous Filipino - indeed, Southeast Asian - governance structures reflect cultural understandings of the obligations and responsibilities embedded in familial relationships (Andaya 2000:21). In terms of pre-modern governance units, early Filipino settlements were known as barangay, which is a Tagalog word originally meaning 'boat' and referring to a boatload of related people, and their dependents (Abinales and Amorose 2005:57). The word barangay continues in the designation of a small polity, as the smallest, most prolific governance unit in the country. There are currently 42,028 barangays in the Philippines (Department of the Interior and Local Government 2014). Traditionally these barangay kinship groups were led by a datu (a chief) and were defined by personal attachment rather than territorial location. The responsibility of a datu was both to lead and to share his wealth with the community and, as a class, datus were 'distinguished by their possession of larger-than-average, well-constructed, sometimes stockade houses filled with ... foreign prestige goods' (Abinales and Amoroso 2005:63). Material possessions denoted status. But this evolving elite did not just siphon off wealth, it also created wealth through production and trade and shared the rewards with the community, particularly through feasting rituals. Through these practices barangays retained 'a high sense of locality and resolute interdependence' and, although the passing centuries yielded significant social change in the form of increased international trade, colonisation, and the introduction of Islam and Christianity, barangays have retained that sense of locality, datu-esque leadership - though modern 'datus' are now elected and paid barangay captains - and interdependence (Abinales and Amoroso 2005: Chapter Two). Thus, Filipino social relations continue to be constituted and defined by a web of subordinate and superordinate social ties that determine roles in the community, relative status, and resource allocation, and oblige reciprocal exchange (Corpus Ong et al, 2015:17). Indeed, as Kerkvleit (2013:228) has observed, the modern democratically-elected barangay captain is empowered, in consultation with barangay councilors, to mediate disputes and handle crimes involving residents, decide how 
resources owned and controlled by the village should be used, and solicit funds and other assistance from municipal, provincial and national government bodies.

In the context of Typhoon Yolanda, humanitarian agencies ascertained key information about community needs through direct engagement with barangay captains, among other consultations. ${ }^{2}$ Lists of the most vulnerable in the community and their needs were drawn up by the captain, the local councilors and the agencies. This information was then verified by the agencies through observations in the communities and through interviews with selected members, and assistance was largely determined and distributed accordingly. This approach appears to align with the barangay governance culture and social organisation, in that the captain's authority was respected and needs were determined both in consultation with key decision-makers in the community and through direct observation of need. So, returning to the feedback from community members about the humanitarian assistance, why did so many express their disappointment that the distributions and support were not equitable and uniform?

Foreign engagement with local power structures can reproduce social inequality and vulnerability - this may have resulted in a call for fairer distribution by those who were not favoured by the captain's distribution lists and felt marginalised (IFRC 2014:21). This does not seem to be the full answer, however, as aid worker interviewees noted the diverse lengths they went to acquire and triangulate feedback from different individuals and groups within a given community, specifically in order to prevent the undue influence of individuals in authority. Activities included: broad consultations in community and small groups and with individuals, regular field observations, anonymous feedback boxes, frontline messaging services, and poster communications (Madianou et al 2015). Moreover, barangay members interviewed as part of this research without the presence of the captains expressed the same dissatisfaction at targeting as those interviewed with authority figures in attendance.

An alternative explanation for the disconnect between international humanitarian responses and Filipino socio-cultural values and practices lies, in part, in acknowledging the Western cultural roots of technical humanitarian assistance and the assumptions about governance, social organisation, and vulnerability that underpin its practice. While in one sense there was a recognition of Filipino social organisation in the form of acknowledged authority of the captain and the need for broad consultation, there was also an imposed valuesystem in the sense that dominant needs-based frameworks differentiate people within a

\footnotetext{
${ }^{2}$ It should be noted that not all agencies followed this approach, particularly private sector actors and some foreign faith-based institutions. Focus on these actors is beyond the scope of this paper, but their targeting and needs-assessment approaches must be analysed as they provide an alternative model to the one described here.
} 
community and distribute material resources based on that designation. In three out of the four barangay-group interviews where captains and/or councilors, and community members were present, all participants collectively expressed dissatisfaction in the final lists that were used to inform goods-distribution, despite apparent prior consultation. And this chimes with interviews with some INGO staff, who noted that while consultation was an important aspect of community participation, non-food items and livelihood support were ultimately given based on a variety of needs assessments, including best practice-informed vulnerability measures. These contrasting norms that originate from the different cultural value systems of barangay communities and INGOs bear closer examination.

\section{Unpacking 'Vulnerability'}

\subsection{Pakikipagkapwa}

When Yolanda came, the typhoon did not select its victims, however when help came it was selective... Food, security and livelihood support should have been shared more widely and then there would be no more poor people (Interview 2015).

On the surface, this reflection by a barangay captain on the humanitarian assistance his community received invokes a basic problem that restricts everything the humanitarian industry does: resource limitations. If humanitarian organisations had unlimited resources, so the train of thought goes, aid would certainly be shared more widely, and communities could recover quicker from the impacts of disasters. This is a key driver of the strategy of humanitarian agencies as they seek larger and longer-term grants from donors. However, the captain's feedback also suggests another important determinant of humanitarian assistance and its reception by recipient communities: shared values and their influence on understandings of what humanitarian objectives should be.

Two core values that help in coping with disasters and everyday hardship in the Philippines are pakikipagkapwa and bayanihan (Bankoff 2007:332; Guerrero 2010; Tuason and Teresa 2013). These values have no direct linguistic translations into English but pakikipagkapwa can generally be understood as 'community' in the sense of a group of people existing in a kind of collective unity, accepting and dealing with others as equals and each holding in regard the dignity and being of the other (Enriquez cited in Guevara 2005:10). Bayanihan refers to deep concern for the community and the need to 'toil' on behalf of others - 'it is working together to our utmost to get the job done' (Leoncini 2005:173; Pertierra 1998:120). These two values are of course defined, understood, and woven into Filipino life in many forms, but a pervasive image that perhaps most clearly expresses the 
bayanihan spirit is the old tradition of community members helping to relocate a family by carrying the entire homestead to the new location upon their backs and shoulders.

Sylvia Guerrero (2010:172) writes that 'the value of pakikipagkapwa (humanness at its highest level) is stressed in Filipino culture - Filipinos give importance to equal treatment of persons - giving high regard for the dignity and well-being of others'. This value requires not taking actions or decisions that would be harmful to the dignity of another person; it is closely linked to community unity and pagkakaisa (consensus), which is considered the highest level of interaction possible Guerrero 2010:172). Given that wealth and material goods designate a form of status, status links to dignity, and dignity is a key feature of interpersonal kinship relations at barangay level and beyond, it follows that distribution and allocation of resources and support is culturally a highly sensitive and political issue, relating to the sense of collective and individual identity. In this context, humanitarian targeting and aid selectivity can have potentially disruptive effects.

\subsection{Targeting and Vulnerability}

The 'targeting' approach of humanitarian organisations is rooted in the assessment of disaster-prone societies through the lens of needs and vulnerabilities. The vulnerability paradigm gained prominence in the 1980s as a means to understand risk in a different way to the technocratic perspective that regarded disasters primarily as physical occurrences requiring technical solutions. The underlying view is that 'social processes generate unequal exposure to risk by making some people more prone to disasters than others, and these inequalities are largely a function of the power relations operative in every society' (Bankoff and Hilhorst 2004:2). The determination of vulnerability is complex - it is understood as produced by a combination of factors derived primarily (though not exclusively) from class, gender and ethnicity - and the approach seeks to combine understandings of communities' exposure to risk with their social, economic and cultural abilities to cope (Bankoff and Hilhorst 2004:2). Despite its complexity it has increasingly become an alternative approach to the modernist/technical paradigm of intervention which dominated in the mid-to-late twentieth century. As Greg Bankoff and Dorothea Hilhorst have noted: 'the powerful insights that vulnerability has to offer have not gone unnoticed. It has increasingly found inclusion in development jargon to identify people particularly in need of interventions' (Bankoff and Hilhorst 2004:2). 
In the context of the Philippines it is a framework actively integrated into humanitarian responses and development programming through disaster management: in the Yolanda response, organisations have, variously, undertaken studies on the 'determinants of vulnerability to natural hazard' (Swiss NGO DRR platform 2014), 'hazard and vulnerability mapping' before and after the typhoon (IOM 2014' Oxfam 2014), and launched assistance programmes to 'help the most vulnerable and fragile populations' (Handicap International 2013). The GoP too refers to the concept in the 2010 Republic Act No. 10121, describing, in Section 3, 'Vulnerable and Marginalised Groups' as 'those that face higher exposure to disaster risk and poverty including, but not limited to, women, children, elderly, differently-abled people, and ethnic minorities'. In turn, these studies and mapping activities feed into needs assessments, which are for many agencies the primary tools used to determine aid provision following a disaster (IFRC n.d.).

What this approach does take into account is the relationship between a hazard, risk and the social processes that expose some communities to them more than others. In terms of disaster management, vulnerability represents the social contribution to risk in a disaster, classically captured in the influential pseudo-formula: Risk = Hazard + Vulnerability (Blaikie et al cited in Hilhorst 2003:38). As a framework for informing assessments of need, it actively encourages a bottom-up, community-participation approach. However, needs assessments influenced by the vulnerability paradigm do not consider the geopolitical and historical roots of the concept itself, and how the framework often reflects very specific cultural values, relating to the way in which certain areas of the world are imagined (Bankoff 2003:5). Although the term vulnerability recognises that exposure to disasters is socially constructed, the form of social construction involved is viewed from an external perspective, and as detached from the power relations and value-sets that are integral to it (Cannon 2008:351).

By definition, the vulnerability paradigm encourages an understanding of those described within its parameters as weak and in need of assistance, ${ }^{3}$ terms that in a disaster context are typically conflated with poverty and marginalisation (Cannon 2008:351). Referring to its conceptual origins, Bankoff connects the vulnerability paradigm to historic discourses of 'tropicality' and 'development', which all 'form part of one and the same essentialising and generalising discourse', relying on Western conceptions of the self and the other (Bankoff 2003:17). Not only are 'vulnerable' populations homogenised in this framework as ostensibly 'helpless victims', but the paradigm also provides justification for

\footnotetext{
${ }^{3}$ The Oxford English Dictionary (2016) defines vulnerability of a person in the following way: '(Of a person) in need of special care, support, or protection because of age, disability, or risk of abuse or neglect'.
} 
the West's continued interference and intervention in the affairs of others (Bankoff 2001:20). Cheryl McEwan (2009:134) has noted that this was evident in early reporting following the 2004 Indian Ocean Tsunami, where technological deficiency - the absence of an early warning system - was blamed as a significant contributor to the large-scale loss of life. Responsibility was placed at the feet of governments who had reportedly ignored calls for such a warning system and therefore had abrogated their responsibilities (McEwan 2009:134-135). Moreover, just a few days after the tsunami disaster hit, media publications in the West were already publishing extensive maps of who was giving what and where, 'emphasising the passivity of the affected countries in the South and the dynamism and the generosity of the ... individuals, government and aid organisations of the North' (McEwan 2009:134-135).

\subsection{Implications of the Vulnerability Frame}

This narrative can be seen in operation nine years later in the response to Typhoon Yolanda. Not only have various actors decried the failure to clearly communicate early warnings as contributing to the high loss of life (Ocon and Neussner 2015; GIZ 2014; Zoleta-Nantes 2013), but the international media extensively covered the international assistance leveraged to affected-communities, largely overlooking individual, local and regional assistance - both organised and ad hoc (The Guardian 2013; Philstar 2013; BBC 2013). Moreover, the very nature of the international humanitarian financing system - with its strict donor-reporting requirements, fundraising needs, and tendency to place inter-agency and intergovernmental territoriality over expertise - virtually necessitates the production of internal and external (public-relations) materials that laud international efforts and direct attention first and foremost on to externally managed interventions at the expense of any other kind. However, while early warning systems certainly failed, and media coverage arguably reflected (rather than distorted) the scale of the international response to the typhoon compared to the domestic non-governmental response (in monetary terms, in the emergency phase, at least), these narratives do not challenge the essentialising discourse of vulnerability that presents those affected by disaster as passive victims needing external, expert assistance.

The problems that can result from this paradigm are twofold. Firstly, the focus on a lack of early warning systems, and the lamentation that people did not heed warnings, reinforces the notion of primitive and passive victimhood. Not only did these communities seemingly fail to establish an effective warning system network, so the argument would go, 
but even when told of an impending devastation they chose to remain in their exposed homes and communities. However, a common recollection in interviews of one of the causes of low evacuation rates in the days preceding the landfall of typhoon Yolanda was the fact that the projected tidal impact on the exposed coastal regions was referred to as a 'storm surge' rather than a tsunami or a destructive wave. While the two are scientifically different phenomena, it was acknowledged that had the threat of the storm surge been likened to that of a tsunami (for a coastal population hit by a wave, the impact would be similar), the coastal regions would have seen higher evacuation rates, particularly due to familiarity with the 2004 Indian Ocean tsunami and the more recent 2011 tsunami in Japan (Community group discussions 2015).

Similar criticism has been levied against participatory community hazard mapping, a key tenet of the Disaster Preparedness and Prevention (DPP) and DRR programmes, which are different but both aimed at reducing community vulnerability to future disasters by reducing risk and increasing preparation. The focus on the efficiency and accuracy of technology in GIS-mapping of community areas exposed to hazard risk has led to the production of maps that are as impressive and detailed in geo-spatial accuracy as they are inadequate in capturing local knowledge of hazards and vulnerabilities (Interview 2015). ${ }^{4}$ In reality it is local knowledge and experience of an area that more often influences the reactions of exposed communities in the advent of a disaster. One manager from a national community-based disaster management organisation commented that many community members do not even know how to read the GIS-generated maps, rendering them useless in a disaster situation (Interview 2015)..$^{5}$

The second and related problem is that these narratives of technological deficiency, insufficient expertise, and passive victimhood can contribute to justifications for an inequitable distribution of international humanitarian resources through established financing mechanisms. Emergency draw-down conditions and arrangements continue to overwhelmingly favour international agencies over national and local organisations and groups in disaster-affected countries (ALNAP 2015). As most bilateral donors rely on selfreporting by their funding recipients, concerns about quality programming and adherence to humanitarian principles and standards are affected by discourses around expertise, notions of vulnerability, and concern over capacity, and this is reflected in the constant selection by these donors of few and familiar partners - specifically large INGOs (CAFOD 2013). As noted

\footnotetext{
${ }^{4}$ Local mapping practices are being developed but they lack funding.

${ }^{5}$ Note: more locally-rooted participatory approaches to DPP are being developed in the University of the Philippines, by Jake Rom Cadag and JC Gaillard.
} 
earlier in the paper, local community organisations that do receive funding often do so, in part, as they are able to navigate and deploy relevant disaster management jargon. And that number is incredibly small. The humanitarian news network IRIN recently reported that 'between 2009-2013 local and national NGOs received 1.6 percent of the humanitarian aid that international donors gave to NGOs, representing 0.2 percent of total humanitarian aid' (IRIN 2014). While there are moves towards reforming emergency funding approaches - the Start Network (2015) offers one example - the fundamental issue of the asymmetrical nature of international humanitarianism remains steadfast. The vulnerability paradigm not only discourages alternative discourses of coping and recovery (Cannon 2008:351), and differentiates individuals and groups within a community in a way that those individuals and groups may not consider accurate or fair, it also reinforces the status quo of the international funding and financing mechanisms.

\section{Towards a New Understanding}

Experiencing and surviving natural disasters and everyday hardship involves much more than retrieving the fragments of a storm-damaged house or repairing fishing nets to maintain a livelihood. Experience and survival are also shaped by everyday political and cultural values and knowledge. These are developed individually, co-constructed within a community, and informed by a diversity of historical and contemporary human and environmental interrelations. These values and areas of knowledge - key aspects of all social groups - shape the way that people define a disaster, the way they look for solutions, and what they even consider to be a disaster and a solution in the first place (Dalisay 2014).

Given the everyday nature of disaster experience in the Philippines, communities have developed a range of adaptive practices aimed at countering, or coping with, the risks and realities of hazards. Houses built on stilts offer a clear example of practical Filipino adaption to hazards such as floods. In terms of indigenous livelihoods and crop production, diversity and fragmentation have historically provided a buffer against a range of meteorological and seismic disruptions. Fragmented farming practices, for example, spread the harvest across separate parcels of land, enabling farmers to retain productivity through wet and dry season cycles, as well as increasing the likelihood of saving crops in one area or another in the event of a disaster (Gultiano and Ulrich 2003:112). Here there is the clear overlap between disaster preparedness and everyday productivity. Survival behaviors can also 
be seen in migration patterns on both a small and large scale. Community members of a barangay in Tacloban noted that the numbers of children at the local school had depleted as families moved further inland to decrease their risk of exposure to another storm surge. Additionally, cognitive responses offer coping mechanisms that are culturally specific and important for both survival and the construction of community identity. As well as pakikipagkapwa and bayanihan previously noted, Bankoff (2003:168) explains the importance of bahala na - a 'leave it to fate' attitude rooted not in despondency but in 'courage and daring' and a 'finely calculated assessment of risks' - and pakikisama, which refers to community sanction for breaking ranks. These, Bankoff explains, all feed into the creation of a sense of shared community that will ensure support for its members in periods of hardship. Finally, and related to all the above, there is a strong narrative of faith and religion in individual and community engagement with their environment and hazards - something not explored in great detail in this paper but of vital importance in the everyday lives of the majority of Filipinos.

The importance of these mechanisms for coping, survival and prosperity in everyday life, as well as in the face of a disaster, lie in their socio-cultural and human-environmental appropriateness for those affected, particularly as this knowledge has been built on historical as well as contemporary experiences, and transmitted through generations. For instance, the desire expressed by the woman in Leyte for an equitable distribution of goods - even if it meant each member received fewer supplies - cannot be understood in simple terms of material envy and dependency. Her individual needs in this instance are perhaps better understood when also placed in the context of wider Filipino values such as community unity, consensus, dignity, and status. As another example, a Filipino aid worker for an international NGO reflected on the psychosocial support programmes offered by her employer and similar organisations, stating that the often individualistic approach of INGOs to post-disaster counselling conflicted with more local traditions of turning to kinship networks for informal support and comfort. The INGO approach here is not inherently wrong, but it is not without its own meaning systems either, and can have a socio-cultural effect of disrupting community support mechanisms and increasing vulnerability in the different sense of marginalisation. Additionally, a frequent call by many community members from various barangays interviewed as part of this research was for purpose-built evacuation centres in each barangay that could safely shield everyone from a hazard and would not involve use of valued community buildings such as schools and churches. Here lies an acknowledgement of likely future hazards (re-emphasising the everyday nature of disaster response in the Philippines) 
but also of community togetherness in survival - namely, sheltering together in the evacuation centre rather than their own homes and enabling important community practices to continue post-disaster, such as education and religious worship.

Capturing these terms of communal knowledge, experiences and priorities for programmatic learning is inevitably complex, and is hindered by certain paradoxes. A difficulty in designing humanitarian assistance around local traditions and knowledge would of course be that they are neither static - as they adapt to relevant outside knowledge, practices and innovations when there is a clear benefit to survival or general prosperity ${ }^{6}-$ nor are they uniform in the sense of all Filipino communities and individuals being motivated by the same norms and values. The same can be said for the dominant Western humanitarian model, which is neither homogenous nor consistent across time and space. And of course, Filipino community and international responses are heavily implicated in, and intertwined with each other, and have been for many decades (Heijmans 2009).

Moreover, international and local knowledge-bases are not equally shared within a given community. Looking at a local level, anthropologist Soledad Dalisay (2014) notes that some knowledge within a single community will be unequally shared due to learning and information-sharing practices that privilege the village elder, for instance; or that certain knowledge will be a source of power and prestige for particular groups - such as a fisherman's knowledge of the sea. These complexities present problems in any attempt to embed local knowledge and contexts within international non-governmental and national government-led models of humanitarian assistance, as they cannot fit the dominant approach of standardisation that informs contemporary international humanitarian engagement. Indeed, not only does taking a 'best practice' approach encourage organisations to standardise aspects of responses for both replicability and measurement purposes, it also currently demands the mainstreaming of certain values and social categories that do not necessarily cohere (for better or worse) with context-specific and culturally-rooted values at the sites of assistance, such as gender, class, age, community participation and so on (van Dijkhorst and Vonhof 2005). Nevertheless, the complexities and contradictions of simultaneously operative and culturally distinct approaches to disaster response (by INGOs, communities and individuals, among others) do not necessarily prohibit co-constituted adaptations to understanding and programming for humanitarian effectiveness. Or, at least, they should not,

\footnotetext{
${ }^{6}$ This, of course, includes mutual learning and adaptation between local and international forms of humanitarian action over the decades.
} 
as long as standardisation, coordination and outcome measurement do not become end goals in themselves.

\section{Conclusion}

The issue of the socio-cultural appropriateness and relevance of the humanitarian assistance to Typhoon Yolanda rests upon two aspects of asymmetry that must be acknowledged before they can even begin to be tackled. Firstly, no humanitarian concept or approach is valueneutral. The concept explored in this paper has been that of vulnerability, but the whole vocabulary of humanitarianism, used to inform and legitimise activities of governmental and non-governmental actors, is laden with competing and contradictory cultural assumptions and norms, and these must be explored in their turn. Appropriateness and relevance as assessment criteria are still useful and important in their emphasis on aligning assistance with local needs and priorities. However, there has to be a clearer consciousness of the values, norms and priorities that international humanitarian actors (the UN, INGOs, for example) bring to the context, as well as of the local culture that assistance will be tailored to. This should include a related analysis of the implications of potential clashes in norms and values as they affect community understandings of what constitutes effective action.

Secondly, the asymmetry of power and monetary resources in the dominant, international humanitarian system perpetuates and reinforces the image of affected communities as passive victims and recipients of assistance. Local mechanisms and values developed for inter-personal and community resilience, survival, and coping over the course of generations in the Philippines - such as pakikipagkapwa, bayanihan, bahala na, pakikisama and so on - can only ever be superficially embedded in humanitarian programmes as long as the programmes continue to: i) be informed by largely Western knowledge and values (such as targeting based on vulnerability measures); and ii) be funded by donors that partner with the few and familiar INGOs who, due to a variety of pressures, require tangible and measurable outputs informed by their own value-sets (such as numbers of 'vulnerable' category recipients reached in an intervention, for instance).

There are clear complexities and contradictions that come with a broadening of appropriateness and relevance to include a more nuanced and reflexive look at the culture of the aid implementers as it contrasts with affected-community norms and values (Hilhorst 2003:44). And this paper has only focused on the practices of a small section of those implementers, predominantly INGOs, and the example of Filipino communities. Nonetheless, there is an evident asymmetric power dynamic that privileges a Western-influenced model of 
assistance. And this privilege can come at the expense of investment in capturing and understanding local and national knowledge and social/cultural practices that frame appropriate action differently through, for example, prioritising equity over targeting. The latter application of local and national priorities and values may not yield straightforward data that prove the effectiveness of a given assistance activity, particularly in a short-term monitoring period, but they may nevertheless contribute to a sense of survival and recovery that more closely accords with personal and community understandings and experiences of disasters over the longer term.

\section{Acknowledgements}

This article appeared in original form as a report I authored for Save the Children UK and the University of Manchester as part of the Humanitarian Effectiveness project (www.humanitarianeffectivenessproject.com). A special thanks to my colleagues Sophie Dicker, Fernando Espada and Juliano Fiori for their immense support in the field study research and on the many edits of this article that followed. Also to the wider steering and advisory groups of the Humanitarian Effectiveness project, whose comments on the final drafts of this article were invaluable. And a final special mention to Louis Amis, whose copyediting skills are second to none and greatly improved the paper.

\section{Funding Sources}

This study formed part of Save the Children UK and the University of Manchester's Humanitarian Effectiveness Project and field research was funded by both the Humanitarian Affairs Team at Save the Children UK and HCRI at the University of Manchester. This study does not reflect Save the Children policy and is the sole responsibility of the author.

\section{References}

Abinales, Patricio N., and Donna J. Amoroso. (2005) State and Society in the Philippines. Oxford: Rowman \& Littlefield Publishers.

ACF. (December 2013) 'A Real-Time Evaluation of ACF International's response to Typhoon Haiyan/Yolanda in the Philippines' [online]. Available at: http://old.alnap.org/resource/20994.aspx [Accessed 3 Feb 2016].

ALNAP and Channel Research. (n.d.) 'Evaluation of Humanitarian Action: Course Material' [online]. Available at:

https://evaluation.msf.org/sites/evaluation/files/evaluation of humanitarian actio n.pdf [Accessed 3 Feb 2016].

ALNAP. (2015) 'State of the Humanitarian System' [online]. Available at: http://sohs.alnap.org [Accessed 3 Feb 2016].

Ashcroft, R. E. (2005) 'Making sense of dignity'. Journal of Medical Ethics, 31, pp. 679-682.

Bankoff, Gregory. (2001) 'Rendering the World Unsafe: 'Vulnerability' as Western Discourse'. Disasters, 25 (1), pp. 19-35.

Bankoff, Gregory. (2003) Cultures of Disaster: Society and Natural Hazard in the Philippines. London: Routledge. 
Bankoff, Gregory. (2004) 'Time is of the Essence: Disasters, Vulnerability and History'. International Journal of Mass Emergencies and Disasters, 22, 3, pp. 23-42.

Bankoff, Gregory and Dorothea Hilhorst. (2004) 'Introduction: Mapping Vulnerability'. In Greg Bankoff, George Frerks and Dorothea Hilhorst (eds.) Mapping Vulnerability: Disasters, Development and People. London: Earthscan.

Bankoff, Gregory. (2007) 'Dangers to going it alone: social capital and the origins of community resilience in the Philippines'. Continuity and Change, 22, pp 327-355.

BBC News. (14 Nov 2013) 'Typhoon Haiyan: Aid in Numbers' [online]. Available at: http://www.bbc.com/news/world-asia-pacific-24899006 [Accessed 3 Feb 2016]

Beck, T. (2006) 'Evaluating Humanitarian Action using the OECD-DAC'. ALNAP, [online]. Available at: http://www.alnap.org/resource/5253 [Accessed 3 Feb 2016]

Benadusi, Mara, Chiara Bramilla, and Bruno Riccio (eds). (2011) Disasters, Development and Humanitarian Aid: New Challenges for Anthropology. Rimini, Italy: Guaraldi.

CAFOD. (April 2013) 'Southern NGO's Access to Humanitarian Funding: A CAFOD Policy Brief' [online]. Available at: www.cafod.org.uk [Accessed 3 Feb 2016].

Cannon, T. (2008) 'Vulnerability, "innocent" disasters and the imperative of cultural understanding'. Disaster and Prevention Management, 17 (3), pp. 350-357.

Corpus Ong, Jonathan. (23 February 2015) 'Hidden Injuries of Humanitarian Relief'. CDAC Network. [online]. Available at: http://www.cdacnetwork.org/i/20150223164553xdmv2/ [Accessed 3 Feb 2016].

Corpus Ong, Jonathan, Jaime Manuel Flores and Pamela Combinido. (2015) 'Obliged to be grateful: How local communities experienced humanitarian actors in the Haiyan Response'. Plan International, World Vision, IOM and UKAid.

Dalisay, Soledad. (Nov 2014) 'Local Knowledges and Sense-Making of Natural Disasters'. University of the Philippines Third World Studies Centre on Public Lecture Series on Natural Disaster. 3 University of the Philippines Diliman, Quezon City.

Department of Social Welfare and Development, Philippines. (11 Dec 2013) 'DSWD, DepEd thank gov't workers, volunteers in E. Visayas for their selflessness' [online]. Available at: http://www.dswd.gov.ph/2013/12/dswd-deped-thank-govt-workers-volunteersin-e-visayas-for-their-selflessness/\#sthash.A6vG019V.dpuf [Accessed 3 Feb 2016]

Department of the Interior and Local Government. (15 July 2014) 'Number of Provinces, Cities, Municipalities and Barangays by Region' [online]. Available at: http://www.dilg.gov.ph/facts-and-figures/Number-of-Provinces-CitiesMunicipalities-and-Barangays-by-Region/30 [Accessed 3 Feb 2016]

Duffield, Mark. (2013) 'Disaster Resilience in the Network Age: Access Denial and the Rise of Cyber Humanitarianism'. DIIS Working Paper, 23, pp 1-32.

Fernandez, Glen, Noralene Uy, and Rajib Shaw. (2012) 'Community-based Disaster Risk Management Experience of the Philippines'. In Community Based Disaster Risk Reduction, edited by Rajib Shaw, 205-231. Bingley, UK: Emerald Books.

Fiori, Juliano with Ben Dempsey and Gareth Owen (2013) 'Humanitarianism Recast'. Save the Children Internal Paper, London: Save the Children.

Gaillard, J C., Jake Rom Cadag, Ryan Christopher P. Viado. (8 August 2014) 'A Hard Act to Follow: Disaster Risk Reduction in the Philippines'. East Asia Forum. [online] Available at: http://www.eastasiaforum.org/2014/08/08/a-hard-act-to-followdisaster-risk-reduction-in-the-philippines/ [Accessed 3 Feb 2016]

Gamburd, Michele Ruth. (2014) The Golden Wave: Culture and Politics After Sri Lanka's Tsunami Disaster, Bloomington: Indiana University Press.

Geertz, Clifford. (1973) The Interpretation of Cultures: Selected Essays. New York, NY: Basic Books.

Geertz, Clifford. (2000) [1983] Local Knowledge: Further Essays in Interpretive Anthropology. New York, NY: Basic Books. 
Giddens, Anthony. (2009) Sociology. $6^{\text {th }}$ Edition. Malden: Polity Press.

GIZ. (2014) 'Assessment of Early Warning Efforts in Leyte for Typhoon Haiyan/Yolanda' [online]. Available at:

http://www.preventionweb.net/files/36860 36860gizassessmentofearlywarningyol. pdf [Accessed 3 Feb 2016]

Government of the Philippines. (2010) 'Republic Act No 10121' [online]. Available at: http://www.gov.ph/2010/05/27/republic-act-no-10121// [Accessed 3 Feb 2016]

Guardian, The. (11 November 2013) 'Enormous aid effort begins in regions devastated by typhoon Haiyan'. [online]. Available at:

http://www.theguardian.com/world/2013/nov/11/enormous-aid-effort-typhoonhaiyan-tacloban [Accessed 3 Feb 2016]

Guerrero, Sylvia H. (2010) 'Filipino Notions of Responsibility: The Shared Identity if the Self and the Other'. In Edith Sizoo (ed.), Responsibility and Cultures of the World: Dialogue Around a Collective Challenge. Brussels, Belgium: P.I.E. Peter Lang.

Guevara, Jaime, (2005) 'Pakikipagkapwa [Sharing/Merging Oneself with Others]'. In Ronaldo Gripaldo (ed), Filipino Cultural Traits. Washington: The Council for Research in Values and Philosophy.

Gultiano S., and P. Ulrich. (2003) 'Philippine Land Holding Patterns and Agricultural Production'. Population Dynamics, Land Availability and Adapting Land Tenure Systems: Philippines, A Case Study, edited by Office of Population Studies. [online]. Available at http://www.cicred.org/Eng/Publications/pdf/MonoPhilippines.pdf [Accessed 27 April 2015]

Handicap International. (25 November 2013) 'Expanding the Emergency Response to Typhoon Haiyan'. [online]. Available at: http://www.handicapinternational.org.uk/resources/latest news/emergencies/20131125-typhoonhaiyan-ensuring-vulnerable-receive-help [Accessed 3 Feb 2016]

Heijmans, Annelies. (2009) 'The Social Life of Community-Based Disaster Risk Reduction: Origin, Politics and Framing'. Disaster Studies Working Paper 20, Aon Benfield UCL Hazard Research Centre.

Hilhorst, Dorothea. (2003) 'Responding to Disasters: Diversity of Bureaucrats, Technocrats and Local People'. International Journal of Mass Emergencies and Disasters, 21 (1), pp. 37-55.

Hoffman and Oliver-Smith, eds. (2002). Catastrophe and Culture: The Anthropology of Disaster. School for American Research Advanced Seminar Series. Oxford: James Currey Ltd.

IASC. (2014) '2014 Global: IASC Inter-agency Humanitarian Evaluation of the Typhoon Haiyan Response' [online]. Available at: http://www.unicef.org/evaldatabase/index 78200.html [Accessed 3 Feb 2016]

IFRC. (2014) 'World Disasters Report: Focus on Culture and Risk'. [online]. Available at: http://www.ifrc.org/Global/Documents/Secretariat/201410/WDR\%202014.pdf [Accessed 3 Feb 2016]

IFRC (13 October 2014). 'One year on from the Bohol earthquake: a new home and a new beginning'. [online]. Available at: http://www.ifrc.org/en/news-and-media/newsstories/asia-pacific/philippines/one-year-on-from-the-bohol-earthquake-a-newhome-and-a-new-beginning-67349/ [Accessed 3 Feb 2016]

IFRC (n.d.) 'Code of Conduct'. http://www.ifrc.org/en/publications-and-reports/code-ofconduct/ [Accessed 4 Feb 2016].

IOM. (7 Nov 2014) 'Typhoon Haiyan'. [online]. Available at: https://www.iom.int/cms/en/sites/iom/home/news-and-views/press-briefingnotes/pbn-2014b/pbn-listing/typhoon-haiyan-anniversary-highl.html [Accessed 3 Feb 2016] 
IRIN. (15 September 2014) 'Rethink needed on humanitarian funding for national INGOs' [online]. Available at: http://www.irinnews.org/report/100610/rethink-needed-onhumanitarian-funding-for-national-ngos [Accessed 3 Feb 2016]

Jacobs, Alex. (2015) 'Pamati Kita: "Let's Listen Together"'. The Humanitarian Practice Network at ODI: The Humanitarian Exchange Magazine, 63.

Kerkvleit, Benedict J. Tria. (2013). Everyday Politics in the Philippines: Class and Status Relations in a Central Luzon Village. Third Edition. Manila: Ateneo de Manila University Press.

Kreuter, Matthew W., Susan N. Lukwago, Dawn C. Bucholtz, Eddie M. Clark and Vetta Sanders-Thompson. (2002) 'Achieving Cultural Appropriateness in Health Promotion Programs: Targeted and Tailored Approaches'. Health, Education and Behaviour, 30 (2), pp. 133-146.

Leoncini, Dante Luis. (2005) 'A Conceptual Analysis of Pakikisama [Getting Along With People]'. In Ronaldo Gripaldo (ed). Filipino Cultural Traits. Washington: The Council for Research in Values and Philosophy.

Lewis, David and David Mosse (eds). (2006) Development Brokers and Translators: The Ethnography of Aid and Agencies. Bloomfield: Kumarian Press Inc.

Lim, Regina Mapua. (2008) 'Philippine Cultural Identity and Traditional Settlements in Development Coming to Terms with Cultural Diversity in a Nation State'. Doctoral Thesis. Oxford Brookes University.

Madianou, Mirca, Liezel Longboan, Jonathan Corpus Ong. (2015) 'Finding a Voice Through Humanitarian Technologies? Communication Technologies and Participation in Disaster Recovery'. International Journal of Communication, 9, pp. 3020-3038.

Manyena, S. B. (2014) 'Disaster resilience: A question of 'multiple faces' and 'multiple spaces?' International Journal of Disaster Risk Reduction, 8, pp. 1-9.

McEwan, Cheryl. (2009) Postcolonialism and Development. Oxon: Routledge Perspectives on Development.

Nakagawa, Yuko and Rajib Shaw. (2004) 'Social Capital: A Missing Link to Disaster Recovery'. International Journal of Mass Emergencies and Disasters, 11, 1, pp. 5-34.

OCHA. (2016) 'Cluster Coordination', [online]. Available at: http://www.unocha.org/whatwe-do/coordination-tools/cluster-coordination [Accessed 21 Dec 2016].

OCHA. (2013) 'Philippines Typhoon Haiyan Sitrep No 24' [online]. Available at: http://reliefweb.int/sites/reliefweb.int/files/resources/OCHAPhilippinesTyphoonHai yanSitrepNo24.pdf. [Accessed 3 Feb 2016].

Ocon, Gemma, and Olaf Neussner. (2015) 'Assessing Early Warning Efforts for Typhoon Haiyan in Leyte'. The Humanitarian Practice Network at ODI: The Humanitarian Exchange Magazine, 63.

OECD-DAC. (2006) 'Key Adaptations Concepts and Terms'. [online]. Available at: http://www.oecd.org/env/cc/36278739.pdf. [Accessed 3 Feb 2016].

Oliver-Smith, Anthony and Susannah Hoffman, eds. 1999. The Angry Earth: Disaster in Anthropological Perspective. London: Routledge, 1999.

Oxfam. (30 April 2014) 'The Right Move? Ensuring durable relocation after typhoon Haiyan'. [online]. Available at: http://policy-practice.oxfam.org.uk/publications/the-rightmove-ensuring-durable-relocation-after-typhoon-haiyan-316093 [Accessed $3 \mathrm{Feb}$ 2016]

Oxfam. (January 2016) 'Humanitarian Quality Assurance: Philippines'. [online]. Available at: http://reliefweb.int/sites/reliefweb.int/files/resources/er-humanitarian-philippineseffectiveness-review-060116-en.pdf [Accessed 3 Feb 2016]

Pertierra, Raul. (1998) 'The Market in Asian Values'. In Josiane Cauquelin, Paul Lim and Birgit Mayer-Konig, eds. Asian Values: Encounter with Diversity. Surrey: Curzon. Pp. 118134. 
Peters, Katie and Mirianna Budimir. (January 2015) 'Typhoon Haiyan: Pushing the Limits of DRR?' The Humanitarian Practice Network at ODI: The Humanitarian Exchange Magazine.

Philstar. (11 Nov 2013) 'Number of nations sending aid for 'Yolanda' victims growing'. [online]. Available at:

http://www.philstar.com/headlines/2013/11/11/1255527/number-nations-sendingaid-yolanda-victims-growing [Accessed 3 Feb 2016].

Rizal, Jose, (2006) Noli me Tangere (Touch me not), Trans. Harold Augenbraum. London: Penguin.

Sanderson, David, and Paul Knox Clarke, with Leah Campbell. (2012) 'Responding to Urban Disasters, Learning from Previous Relief and Recovery Operations'. ALNAP Lessons Paper. [online]. Available at: http://www.alnap.org/resource/7772. [Accessed 3 Feb 2016].

Start Network. 2015. [online]. Available at: http://www.start-network.org/how/start-fund/ [Accessed 3 Feb 2016]

Strömberg, David. (2007) 'Natural Disasters, Economic Development, and Humanitarian Aid'. The Journal of Economic Perspectives, 21 (3), pp. 199-222.

Swiss NGO DRR Platform. (July 2014) 'Disaster Risk Reduction and Management in the Philippines'. [online]. Available at: http://drrplatform.org/images/DocPub/RiskAssessment.pdf [Accessed 3 Feb 2016]

Tuason, Ma Teresa G. (2013) 'Those who were born poor: A qualitative study of Philippine poverty'. Qualitative Psychology, 1(S), pp. 95-115.

UNISDR. 30 August 2007. 'Terminology'.[online]. Available at: http://www.unisdr.org/we/inform/terminology [Accessed 3 Feb 2016]

UNISDR. (September 2006) 'Global Survey of Early Warning Systems: An assessment of capacities, gaps and opportunities towards building a comprehensive global early warning system for all natural hazards'. United Nations. [online]. Available at: http://www.unisdr.org/2006/ppew/info-resources/ewc3/Global-Survey-of-EarlyWarning-Systems.pdf [Accessed 3 Feb 2016]

UNISDR. (n.d.) 'Hyogo Framework for Action'. [online]. Available at: http://www.unisdr.org/we/coordinate/hfa [Accessed 3 Feb 2016]

United Nations. (1948) 'Universal Declaration of Human Rights' [online] http://www.un.org/en/universal-declaration-human-rights/ [Accessed 3 Feb 2016]

Van Dijkhorst Hilde, and Suzette Vonhof. (2005) 'Gender and Humanitarian Aid: A Literature Review of Policy and Practice'. Cordaid. [online]. Available at: http://www.caritas.eu/sites/default/files/genderandhumanitarianaidfinalreport.pdf [Accessed 3 Feb 2016]

Van Voorst, Roanne, Ben Wisner , Jörgen Hellman, Gerben Nooteboom. (2015) 'Introduction to the "Risky Everyday"', Disaster Prevention and Management, 24 (4), pp.1-6.

Watson Andaya, Barbara. (2000) 'Introduction'. In Barbara Watson Andaya (ed.) Other Pasts: Women, Gender and History in Early Modern Southeast Asia, Honolulu: Center for Southeast Asia Studies, University of Hawai'i at Manoa.

'Vulnerable', (2006) Oxford Dictionaries, [online]. Available at: http://www.oxforddictionaries.com/definition/english/vulnerable [Accessed 27 April 2015].

WCDR. (18 March 2015) 'Sendai Framework for Disaster Risk Reduction'. [online]. Available at: http://www.wcdrr.org/uploads/Sendai Framework for Disaster Risk Reduction 2 015-2030.pdf [Accessed 3 Feb 2016] 
Wingard, Jessie, and Anne-Sophie Brändlin. (10 November 2013) 'Philippines: A Country Prone to Natural Disasters'. Deutsche Welle [online]. Available at:

http://www.dw.de/philippines-a-country-prone-to-natural-disasters/a-17217404 [Accessed 3 Feb 2016]

Wisner, Ben, Piers Blaikie, Terry Cannon and lan Davis. (2003) At Risk: Natural hazards, people's vulnerability and disasters. Second edition. London: Routledge.

Zoleta-Nantes, Doracie. (13 November 2013) 'Typhoon Haiyan: A Perfect Storm of Corruption and Neglect'. The Conversation. [online]. Available at:

http://theconversation.com/typhoon-haiyan-a-perfect-storm-of-corruption-andneglect-20149. [Accessed 3 Feb 2016]. 